\begin{tabular}{|c|l|}
\hline Title & $\begin{array}{l}\text { Electrochemical Oxidative Formation and Reductive Desorption of a Self-A ssembled Monolayer of Decanethiol on a } \\
\text { Au(111) Surface in KOH Ethanol Solution }\end{array}$ \\
\hline Author(s) & Sumi, Takayoshi; Uosaki, Kohei \\
\hline Citation & $\begin{array}{l}\text { Journal of Physical Chemistry B, 108(20), 6422-6428 } \\
\text { https://doi.org/10.1021/j049558+ }\end{array}$ \\
\hline Issue Date & 200405-20 \\
\hline Doc URL & http://hdl.handle.net/2115/50227 \\
\hline Type & article \\
\hline File Information & JPCB108-20_6422-6428.pdf \\
\hline
\end{tabular}

Instructions for use 


\title{
Electrochemical Oxidative Formation and Reductive Desorption of a Self-Assembled Monolayer of Decanethiol on a Au(111) Surface in KOH Ethanol Solution
}

\author{
Takayoshi Sumi and Kohei Uosaki* \\ Physical Chemistry Laboratory, Division of Chemistry, Graduate School of Science, Hokkaido University, \\ Sapporo 060-0810, Japan
}

Received: January 31, 2004; In Final Form: March 11, 2004

\begin{abstract}
Electrochemical oxidative adsorption and reductive desorption of a self-assembled monolayer (SAM) of decanethiol on a $\mathrm{Au}(111)$ single crystal electrode were examined in $0.1 \mathrm{M} \mathrm{KOH}$ ethanol solution containing various concentrations of decanethiol ranging from $1 \mu \mathrm{M}$ to $1 \mathrm{mM}$. Anodic and cathodic current peaks corresponding to the adsorption and desorption of decanethiol, respectively, were observed in cyclic voltammograms of a $\mathrm{Au}(111)$ single crystal electrode obtained in $0.1 \mathrm{M} \mathrm{KOH}$ ethanol solution containing more than $10 \mu \mathrm{M}$ of decanethiol. Positions of both peaks depended on the concentration of decanethiol, and they shifted negatively by ca. $0.057 \mathrm{~V} /$ decade with increase in decanethiol concentration. This result confirms that the adsorption and desorption of decanethiol is a one-electron process. The reductive charge, which consists of desorption charge and capacitive charge, increased when the sweep rate was decreased and the decanethiol concentration was increased and reached the saturated value of $103( \pm 5 \%) \mu \mathrm{C} \mathrm{cm}^{-2}$, which corresponds to the reductive charge of thiol SAM of full coverage with a $(\sqrt{ } 3 \times \sqrt{3}) R 30^{\circ}$ structure. Potentiostatic SAM formation was also investigated by holding the potential at $+0.1 \mathrm{~V}$. The reductive charge, i.e., the coverage of the SAM, increased with time and reached the saturated value of $103( \pm 5 \%) \mu \mathrm{C} \mathrm{cm}$, corresponding to full coverage, after holding the potential at $+0.1 \mathrm{~V}$ for a certain period of time. The time when the amount of adsorbed thiolate reached full coverage depended on the concentration of decanethiol. The higher the concentration was, the faster full coverage was reached. The desorption peak shifted negatively as the holding time at $+0.1 \mathrm{~V}$ was increased even after the adsorbed amount had reached full coverage. These results suggest that the ordering of decanethiol SAMs requires a much longer time than the time required for full coverage adsorption. The position of the reductive desorption peak was independent of the thiol concentration if the electrode was kept at $+0.1 \mathrm{~V}$ for long enough so that a highly ordered SAM was formed. The cathodic peak shifted negatively as the sweep rate was increased, showing that reductive desorption of the SAM was rather slow. The rate constant for the reductive desorption was determined from the potential dependent peak shift to be $0.24 \mathrm{~s}^{-1}$, which is in good agreement with the value obtained for a SAM prepared without potential control, indicating that the quality of the electrochemically prepared SAM is as good as that of the SAM prepared nonelectrochemically.
\end{abstract}

\section{Introduction}

Construction of organic molecular layers on solid surfaces is an important subject not only for fundamental science but also for a wide range of applications such as wetting control, corrosion inhibition, and molecular and bio-electronic devices. A self-assembly technique in solution has been extensively used to construct organic layers because a well-ordered structure can be prepared easily without the requirement of expensive equipment, which is essential for the formation of an organic molecular layer in ultrahigh vacuum. ${ }^{1,2}$ The most extensively studied self-assembly system is self-assembled monolayers (SAMs) of alkanethiols on various metals, especially gold..$^{3,4}$ SAMs with a wide variety of functionalities can be constructed using thiol molecules with terminal groups having special functions. ${ }^{5,6}$ The self-assembly of thiols on metals such as gold and silver is achieved by chemical bond formation between the substrate atoms and sulfur atoms of alkanethiols and hydrophobic interaction among the alkyl chains. ${ }^{7}$ The formation

* To whom correspondence should be addressed. Phone: +81-11-7063128. Fax: +81-11-706-3440. E-mail: uosaki@pcl.sci.hokudai.ac.jp. process and the structure of alkanethiol SAMs on gold single crystal surfaces have been studied in detail by using various techniques, including IR spectroscopy, ${ }^{8-10}$ quartz crystal microbalance (QCM), ${ }^{11,12}$ scanning tunneling microscopy (STM),${ }^{13-15}$ atomic force microscopy (AFM), ${ }^{16,17} \mathrm{X}$-ray diffraction, ${ }^{18}$ X-ray photoemission spectroscopy (XPS), ${ }^{19,20}$ second harmonic generation spectroscopy $(\mathrm{SHG}),{ }^{21}$ sum frequency generation spectroscopy (SFG), ${ }^{22,23}$ and impedance spectroscopy. ${ }^{24,25}$ It is now well-known that the alkanethiols are arranged in striped structures when the coverage is low and in a $(\sqrt{3} \times$ $\sqrt{ } 3) R 30^{\circ}$ and/or $c(4 \times 2)$ structure with a tilt angle of ca. $30^{\circ}$ from the surface normal when the coverage becomes high. ${ }^{13-15}$ STM has also revealed that there are many defects in the SAMs such as missing rows and pits. ${ }^{26-28}$ The missing row defects are attributed to the orientational and translational domain boundaries, and the pits were revealed to be vacancy islands of the gold atoms. We have found that the density of the pits is strongly dependent on the solvent and temperature employed for the self-assembly. ${ }^{29,30}$

Since Widrig et al. reported that an alkanethiol SAM is desorbed from the gold surface by a one-electron reduction 
process in an alkaline aqueous solution, ${ }^{31}$ many electrochemical studies on this reaction have been carried out. ${ }^{32-42}$

$$
\mathrm{Au}-\mathrm{SR}+\mathrm{e}^{-} \rightarrow \mathrm{Au}+\mathrm{RS}^{-}
$$

The area, shape, and position of the cathodic peak for the reductive desorption provide useful information on the SAM such as the adsorbed amount, stability, adsorption energy, orientation, and substrate morphology. For example, it was found that the longer the alkyl chain is, the more negative the reductive peak is, reflecting stronger van der Waals attractive interaction among alkyl chains. ${ }^{31}$ The reductive desorption process has been investigated by FT-IR spectroscopy ${ }^{43,44}$ electrochemical QCM, ${ }^{45,46}$ and in situ STM. ${ }^{47-49}$ We have also carried out an in situ STM investigation of the reductive desorption process of hexanethiol SAMs on $\mathrm{Au}(111)$ surfaces both in $\mathrm{H}_{2} \mathrm{SO}_{4}$ and $\mathrm{KOH}$ aqueous solutions and found that the desorption of the SAM was initiated from the defects of the SAM, i.e., missing rows and the edges of vacancy islands. It was also found that desorbed thiolates formed aggregates in $\mathrm{H}_{2} \mathrm{SO}_{4}$, but a reconstructed $\mathrm{Au}(111)$ surface, i.e., clean surface of $\mathrm{Au}(111)$, was exposed after the desorption of the SAM in $\mathrm{KOH}$ solution. ${ }^{50}$

When the electrode potential is scanned back in the positive direction after an alkanethiol monolayer has been desorbed cathodically, an anodic peak corresponding to the oxidative readsorption of a fraction of the desorbed alkanethiolates remaining on and/or near the electrode surface, i.e., the reverse reaction of the reductive desorption given by eq 1 , is observed. . $^{31,38,39}$

Weisshaar et al. showed that a thiolate SAM, the structure and interfacial properties of which are similar to those of a SAM formed in ethanol solution without potential control, could be constructed anodically in an alkaline ethanol solution containing alkanethiol due to the reverse reaction of eq $1 .{ }^{51}$ Although anodic oxidative formation of thiolate SAM seems to be an interesting alternative for SAM formation, only a few investigations have been carried out, and details are not known. ${ }^{52-61}$ Recently, we briefly reported that quantitative analysis of the reductive desorption of an electrodeposited thiolate layer provided us with useful information about the formation process of a SAM such as the time dependency of the adsorbed amount and the order of the SAM. ${ }^{62}$

In this work, we studied in detail the anodic oxidative adsorption and cathodic reductive desorption of decanethiol layers on $\mathrm{Au}(111)$ electrodes in $0.1 \mathrm{M} \mathrm{KOH}$ ethanol solutions containing various concentrations of decanethiol. The effects of sweep rate and thiol concentration under the condition of continuous potential cycling as well as the effects of holding time and thiol concentration under the condition of potentiostatic oxidative SAM formation on the amount of adsorbed thiolate and the order of the SAM were evaluated from the charge and position of the reductive peak, respectively. The times required to reach saturated coverage and high order were shorter when the decanethiol concentration was higher. A much longer time was required for ordering than for full coverage adsorption of the decanethiol SAM.

\section{Experimental Section}

n-Decanethiol $\left(\mathrm{CH}_{3}\left(\mathrm{CH}_{2}\right)_{9} \mathrm{SH}: \mathrm{C} 10 \mathrm{SH}\right)$, ethanol, and $\mathrm{H}_{2} \mathrm{SO}_{4}$ were all reagent grade chemicals obtained from Wako Pure Chemicals, and $\mathrm{KOH}$, which was of semiconductor grade, was purchased from Aldrich. They were used without further purification. Water was purified using a Milli-Q purification system (Yamamoto, WQ-500). Ultrapure Ar gas (99.9995\%)

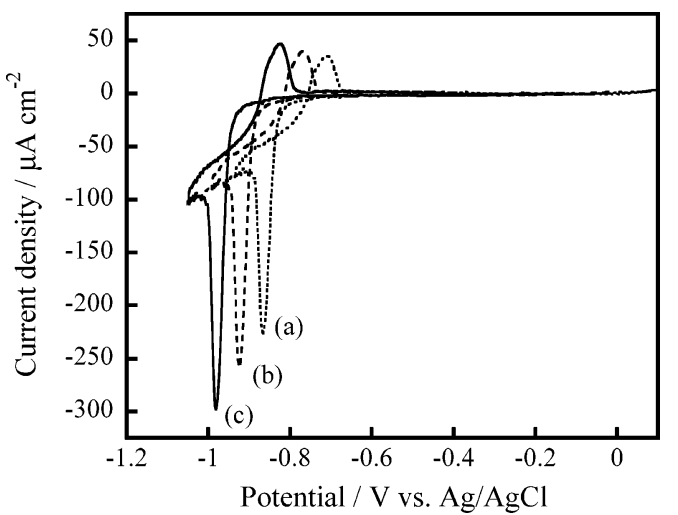

Figure 1. Cyclic voltammograms of a $\mathrm{Au}(111)$ single crystal electrode measured in $0.1 \mathrm{M} \mathrm{KOH}$ ethanol solutions containing (a) $10 \mu \mathrm{M}$, (b) $100 \mu \mathrm{M}$, and (c) $1 \mathrm{mM}$ of $\mathrm{C} 10 \mathrm{SH}$. Sweep rate: $0.2 \mathrm{~V} \mathrm{~s}^{-1}$.

was purchased from Air Water. A Au(111) single crystal was prepared from a gold wire $(99.999 \%$ pure, $\phi=1 \mathrm{~mm}$, Tanaka Precious Metal) by the Clavilier method. ${ }^{63}$ The Au(111) surface was flame-annealed in a hydrogen flame and gradually cooled under an argon stream prior to each measurement.

Electrochemical measurements were carried out in a threecompartment electrochemical cell with a hanging meniscus configuration in $0.1 \mathrm{M} \mathrm{KOH}$ ethanol solutions containing various concentrations of C10SH using a potentiostat (Hokuto Denko, HA-151) and a function generator (Hokuto Denko, HB111). Cyclic voltammograms (CVs) were recorded using an $\mathrm{X}-\mathrm{Y}$ recorder (Graphtec, WX1200). The electrode potential was referred to a $\mathrm{Ag} / \mathrm{AgCl}$ (saturated $\mathrm{NaCl}$ ) electrode, and a $\mathrm{Pt}$ wire was used as a counter electrode. The electrolyte solution was deaerated by bubbling Ar gas for at least 30 min before each experiment. The high quality and cleanliness of the Au(111) single crystal were ensured by recording CVs in $0.1 \mathrm{M}$ $\mathrm{H}_{2} \mathrm{SO}_{4}$ solution. The obtained $\mathrm{CV}$ s were in agreement with those for clean $\mathrm{Au}(111)$ electrodes reported previously. ${ }^{64,65}$ The real area of the $\mathrm{Au}(111)$ single crystal electrode estimated from cathodic current corresponding to the reduction of $\mathrm{Au}$ oxide was $0.055 \mathrm{~cm}^{2}$.

\section{Results and Discussion}

Cyclic Voltammetry. Figure 1 shows CVs of a $\mathrm{Au}(111)$ single crystal electrode measured in $0.1 \mathrm{M} \mathrm{KOH}$ ethanol solutions containing (a) $10 \mu \mathrm{M}$, (b) $100 \mu \mathrm{M}$, and (c) $1 \mathrm{mM}$ C10SH. Since the $K_{\mathrm{a}}$ of $\mathrm{C} 10 \mathrm{SH}$ is ca. $10^{66,67}$ and the $\mathrm{pH}$ of $0.1 \mathrm{M} \mathrm{KOH}$ ethanol solution is ca. 13, C10SH is expected to

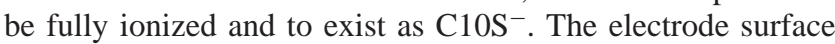
was placed in contact with the electrolyte solution while the potential of the electrode was held at $-1.0 \mathrm{~V}$, a potential at which adsorption of $\mathrm{C} 10 \mathrm{~S}^{-}$was not expected. All of the CVs shown in Figure 1 were recorded after the potential had been continuously cycled between -1.0 and $+0.1 \mathrm{~V}$ at the sweep rate of $0.2 \mathrm{~V} \mathrm{~s}^{-1}$ several times until the shape of the CVs showed no further change. Thus, they represent steady states of the adsorption and desorption of thiolate molecules in each ethanol solution. Anodic peaks corresponding to the oxidative adsorption of thiolate were observed at $-0.71,-0.77$, and $-0.82 \mathrm{~V}$ in 10 $\mu \mathrm{M}, 100 \mu \mathrm{M}$, and $1 \mathrm{mM} \mathrm{C10SH}$ solutions, respectively, when the potential was swept in the positive direction. When the potential was scanned back in the negative direction from +0.1 $\mathrm{V}$, cathodic peaks corresponding to the reductive desorption of C10SH SAMs were observed at $-0.87,-0.93$, and $-0.98 \mathrm{~V}$ in $10 \mu \mathrm{M}, 100 \mu \mathrm{M}$, and $1 \mathrm{mM} \mathrm{C10SH}$ solutions, respectively. 


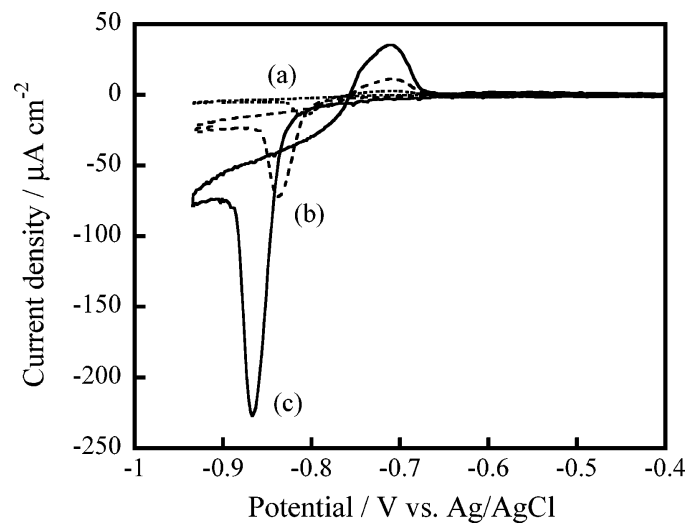

Figure 2. Cyclic voltammograms of a $\mathrm{Au}(111)$ single crystal electrode measured in $0.1 \mathrm{M} \mathrm{KOH}$ ethanol solution containing $10 \mu \mathrm{M}$ of $\mathrm{C} 10 \mathrm{SH}$. Sweep rates: (a) $0.01 \mathrm{~V} \mathrm{~s}^{-1}$, (b) $0.05 \mathrm{~V} \mathrm{~s}^{-1}$, and (c) $0.2 \mathrm{~V} \mathrm{~s}^{-1}$.

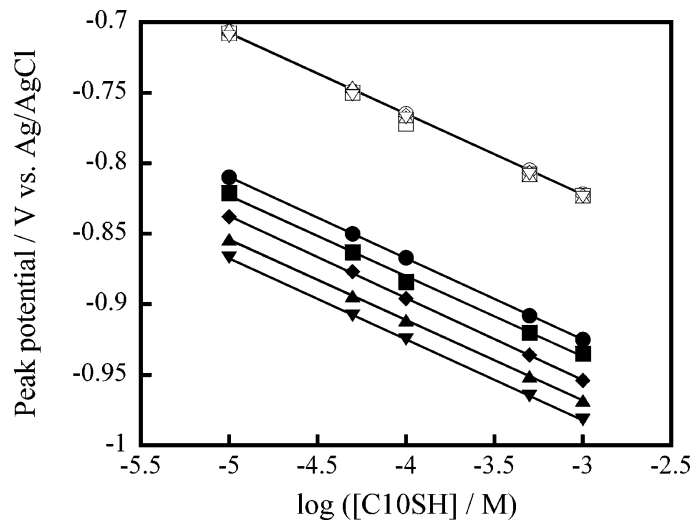

Figure 3. Anodic (filled) and cathodic (unfilled) peak potentials as a function of $\mathrm{C} 10 \mathrm{SH}$ concentration in $0.1 \mathrm{M} \mathrm{KOH}$ ethanol solution. Sweep rates: $\bullet, \bigcirc, 0.01 \mathrm{~V} \mathrm{~s}^{-1} ; \mathbf{\square}, \square, 0.02 \mathrm{~V} \mathrm{~s}^{-1} ; \diamond, \diamond, 0.05 \mathrm{~V} \mathrm{~s}^{-1}$; $\boldsymbol{\Delta}, \Delta, 0.1 \mathrm{~V} \mathrm{~s}^{-1}$; and $\mathbf{\nabla}, \nabla, 0.2 \mathrm{~V} \mathrm{~s}^{-1}$.

No clear peaks were observed in a solution containing $1 \mu \mathrm{M}$ $\mathrm{C} 10 \mathrm{SH}$. Similar results were observed at the sweep rate of 0.02 $\mathrm{V} \mathrm{s}^{-1}$ as previously reported. ${ }^{62}$ The CVs recorded under the present conditions did not change with potential cycling. This is in contrast to results obtained in aqueous solutions containing no thiol in which CVs of the thiol SAM-modified gold electrode showed that both the reductive desorption peak and oxidative readsorption peak became smaller on repetitive potential cycling because some of the desorbed thiolates diffused away from the electrode surface before the readsorption. ${ }^{39}$

Figure 2 shows CVs of a $\mathrm{Au}(111)$ single crystal electrode measured in a $0.1 \mathrm{M} \mathrm{KOH}$ ethanol solution containing $10 \mu \mathrm{M}$ $\mathrm{C} 10 \mathrm{SH}$ at sweep rates of (a) 0.01 , (b) 0.05 , and (c) $0.2 \mathrm{~V} \mathrm{~s}^{-1}$. While the peak position of the anodic peak corresponding to oxidative thiolate adsorption was at $-0.71 \mathrm{~V}$ regardless of the sweep rate, the position of the cathodic peak corresponding to desorption of the thiolate SAM shifted negatively as the sweep rate became faster.

Concentration dependencies of the positions of both peaks at various sweep rates are summarized in Figure 3. Both peaks shifted negatively with an increase in decanethiol concentration by ca. $0.057 \mathrm{~V} /$ decade at all sweep rates. The half-wave potentials can be estimated by the following Nernst equation, assuming that the cathodic and anodic reactions are given by the forward and reverse reactions given by eq $1:^{68}$

$$
E_{1 / 2}=E_{0}^{\prime}+\frac{R T}{F} \ln \left(\frac{a_{\mathrm{C} 10 \mathrm{~S}-\mathrm{Au}}}{a_{\mathrm{C} 10 \mathrm{~S}}-a_{\mathrm{Au}}}\right)
$$

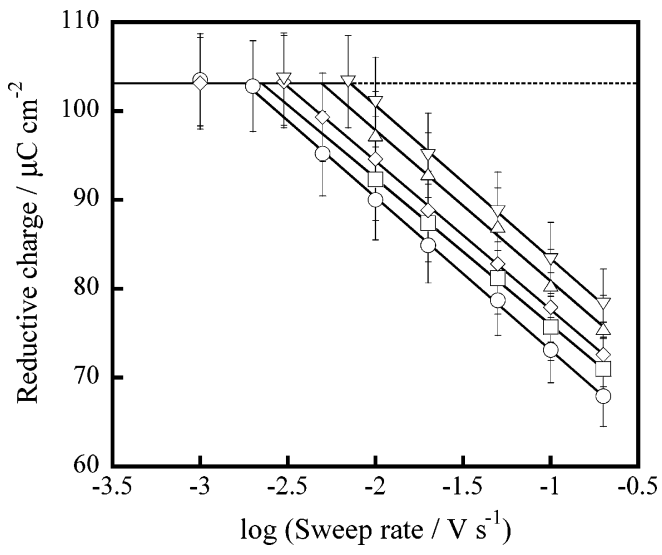

Figure 4. Reductive charge as a function of the logarithm of sweep rate in $0.1 \mathrm{M} \mathrm{KOH}$ ethanol solutions containing $\bigcirc, 10 \mu \mathrm{M} ; \square, 50 \mu \mathrm{M}$; $\diamond, 100 \mu \mathrm{M} ; \Delta, 500 \mu \mathrm{M}$; and $\diamond, 1 \mathrm{mM}$ of $\mathrm{C} 10 \mathrm{SH}$.

where $a_{\mathrm{C} 10 \mathrm{~S}-\mathrm{Au}}, a_{\mathrm{C} 10 \mathrm{~S}^{-}}$, and $a_{\mathrm{Au}}$ are the activities of the decanethiol SAM, $\mathrm{C}^{-} \mathrm{S}^{-}$in solution, and gold, respectively. Since $a_{\mathrm{Au}}$ is 1 , eq 2 can be written for $298.15 \mathrm{~K}$ as

$$
E_{1 / 2}=E_{0}^{\prime}+0.059 \log \left(\frac{a_{\mathrm{C} 10 \mathrm{~S}-\mathrm{Au}}}{a_{{\mathrm{C} 10 \mathrm{~S}^{-}}}}\right)
$$

Alkanethiol SAMs are known to have several phases and $a_{\mathrm{C} 10 \mathrm{~S}-\mathrm{Au}}$ should depend on the phase, i.e., the order of the SAM. ${ }^{13,14}$ Thus, the redox potential should depend on both the alkanethiol concentration and the order of the SAM. If the order of the SAM, i.e., $a_{\mathrm{C} 10 \mathrm{~S}-\mathrm{Au}}$, is assumed to be independent of the thiol concentration, eq 3 becomes

$$
E_{1 / 2}=E_{0}^{\prime}-0.059 \log \left(a_{{\mathrm{C} 10 \mathrm{~S}^{-}}^{-}}\right)-\mathrm{const}
$$

and the peak potential is expected to change with increase in decanethiol concentration by $0.059 \mathrm{~V} /$ decade. This is in excellent agreement with the experimental results presented in Figure 3, showing that the peak positions are mainly controlled by the decanethiol concentration. This result indicates that $a_{\mathrm{C} 10 \mathrm{~S}-\mathrm{Au}}$ is essentially constant at a given concentration during potential cycling and suggests that the time scale in the sweep rates between 0.01 and $0.2 \mathrm{~V} \mathrm{~s}^{-1}$ is short compared with the time required for the reorganization/ordering of the SAM, leading to a significant change in the $a_{\mathrm{C} 10 \mathrm{~S}-\mathrm{Au}}$. Thus, the reductive desorption and oxidative adsorption of the decanethiol proceeded as shown in eq 1 and its reverse reaction, respectively. The reasons for the sweep rate dependence of the cathodic peak position will be discussed later.

The reductive charge increased as the decanethiol concentration was increased (Figure 1) or as the sweep rate was decreased (Figure 2). Figure 4 shows reductive charge as a function of the logarithm of sweep rate for various concentrations of the thiol. It should be noted that not only the Faradaic charge associated with the desorption of decanethiol SAM but also the capacitive charge arising from the difference between the double layer capacitance of the thiol-covered gold electrode and that of the bare gold electrode contribute to the experimentally observed reductive charge. ${ }^{38,39}$ The reductive charge linearly increased with increase in the logarithm of sweep rate and reached the saturated value of $103( \pm 5 \%) \mu \mathrm{C} \mathrm{cm}^{-2}$ in all cases. Reductive charges at a given sweep rate were higher in a solution with a higher concentration in the region in which a linear relation was observed between the reductive charge and the logarithm of sweep rate, but the saturated value of 103 

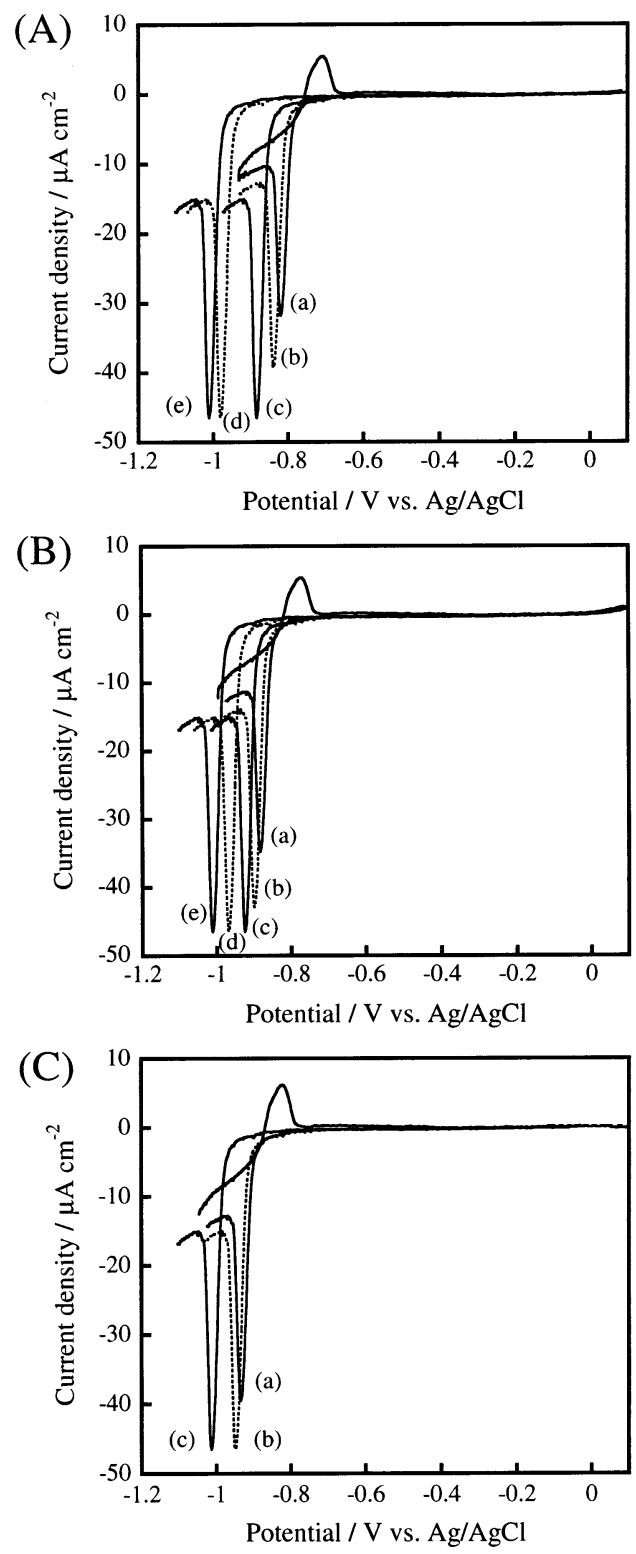

Figure 5. Linear sweep voltammograms of a $\mathrm{Au}(111)$ electrode measured in $0.1 \mathrm{M} \mathrm{KOH}$ ethanol solutions containing (A) $10 \mu \mathrm{M}$, (B) $100 \mu \mathrm{M}$, and (C) $1 \mathrm{mM}$ of C10SH after holding the potential at +0.1 $\mathrm{V}$ for various time periods. Holding times: (A) (a) $0 \mathrm{~min}$, (b) $5 \mathrm{~min}$, (c) $10 \mathrm{~min}$, (d) $30 \mathrm{~min}$, and (e) $60 \mathrm{~min}$; (B) (a) $0 \mathrm{~min}$, (b) $3 \mathrm{~min}$, (c) 6 min, (d) $10 \mathrm{~min}$, and (e) $20 \mathrm{~min}$; (C) (a) $0 \mathrm{~min}$, (b) $2 \mathrm{~min}$, and (c) 10 min. Sweep rate: $0.02 \mathrm{~V} \mathrm{~s}^{-1}$.

$( \pm 5 \%) \mu \mathrm{C} \mathrm{cm} \mathrm{cm}^{-2}$ was constant regardless of the solution concentration. This value is in agreement with the values reported for the reductive desorption of a SAM with saturated coverage of a $(\sqrt{3} \times \sqrt{ } 3) R 30^{\circ}$ structure formed in an ethanol solution containing only alkanethiol without potential control. ${ }^{38,39,46}$ It has been demonstrated that $103( \pm 10 \%) \mu \mathrm{C} \mathrm{cm} \mathrm{cm}^{-2}$ consists of a Faradaic charge of $73.3 \mu \mathrm{C} \mathrm{cm}^{-2}$ for one-electron reduction of a SAM with saturated coverage of a $(\sqrt{3} \times \sqrt{ } 3)$ $R 30^{\circ}$ structure and capacitive charge of $30 \mu \mathrm{C} \mathrm{cm}{ }^{-2} \cdot 38,39,58,69$

Potentiostatic Monolayer Formation. Since the area and position of the cathodic peak reflect the amount of adsorption and the order of SAM, the formation process can be followed in detail by carrying out linear sweep reductive desorption measurements after holding the potential of the electrode at a certain value for various periods of time. The $\mathrm{Au}(111)$ single crystal electrode was placed in contact with $0.1 \mathrm{M} \mathrm{KOH}$ ethanol solutions containing $10 \mu \mathrm{M}, 100 \mu \mathrm{M}$, and $1 \mathrm{mM} \mathrm{C} 10 \mathrm{SH}$ at

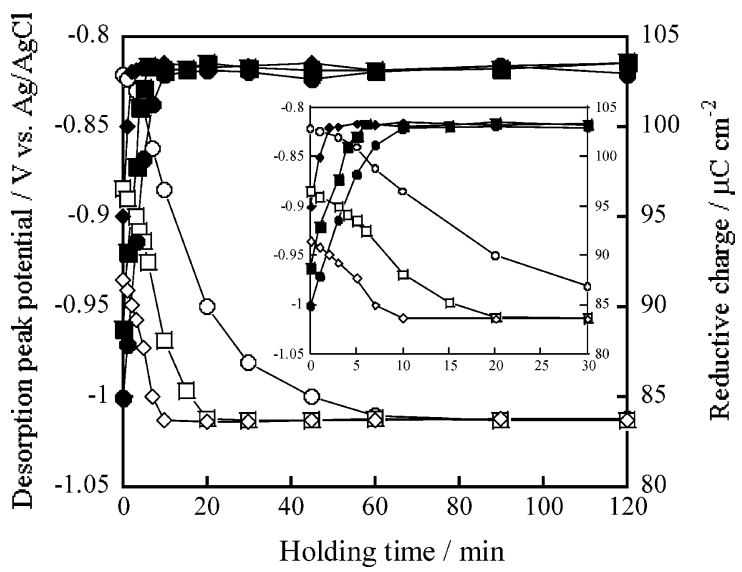

Figure 6. Cathodic peak potential (unfilled) and charge of the cathodic wave (filled) as a function of holding time at $+0.1 \mathrm{~V}$ in $0.1 \mathrm{M} \mathrm{KOH}$ ethanol solutions containing $10 \mu \mathrm{M}(\bigcirc, \bullet), 100 \mu \mathrm{M}(\square, \boldsymbol{\square})$, and 1 $\mathrm{mM}(\diamond, \diamond)$ of decanethiol. Inset shows the initial stage of the relations. Error bars are omitted for the clarification, and all data of reductive charge contain $\pm 5 \%$ error.

around $-1.0 \mathrm{~V}$, a potential at which no adsorption occurred, and then the potential was scanned to $+0.1 \mathrm{~V}$, a potential at which the adsorption of $\mathrm{C}_{10 \mathrm{~S}^{-}}$was expected to occur, at the sweep rate of $0.02 \mathrm{~V} \mathrm{~s}^{-1}$. After holding the potential at $+0.1 \mathrm{~V}$ for a certain time period, the potential was scanned negatively until a cathodic peak current was passed.

Figure 5 shows linear sweep voltammograms obtained after the potential had been held at $+0.1 \mathrm{~V}$ in (A) $10 \mu \mathrm{M}$, (B) 100 $\mu \mathrm{M}$, and (C) $1 \mathrm{mM} \mathrm{C10SH}$ solutions for various periods of time. It is clear that the peak area increased and that the peak position shifted negatively as the holding time was increased in all cases.

Results of the holding time dependencies of position and charge of the cathodic peak are summarized in Figure 6. Note that time 0 in Figure 6 means continuous potential cycling.

The reductive charge increased with increase in the time for which the potential was held at $+0.1 \mathrm{~V}$ and reached $103( \pm 5 \%)$ $\mu \mathrm{C} \mathrm{cm}^{-2}$, which corresponds to saturated coverage, in $\mathrm{C} 10 \mathrm{SH}$ solutions with concentrations between $10 \mu \mathrm{M}$ and $1 \mathrm{mM}$ if sufficient time was allowed, although the time required to reach this value depended on the decanethiol concentration. In $10 \mu \mathrm{M}$ $\mathrm{C} 10 \mathrm{SH}$ solution, the reductive charge increased from $85( \pm 5 \%)$ $\mu \mathrm{C} \mathrm{cm}^{-2}$ at $0 \mathrm{~min}$, i.e., under a continuous cycling, to 103 $( \pm 5 \%) \mu \mathrm{C} \mathrm{cm}^{-2}$, i.e., a saturated amount, at ca. $10 \mathrm{~min}$. A saturated coverage was reached faster in the thiol solution of higher concentration. It was reached in $6 \mathrm{~min}$ in $100 \mu \mathrm{M} \mathrm{C10SH}$ solution and in $2 \mathrm{~min}$ in $1 \mathrm{mM} \mathrm{C10SH}$ solution. These results confirm that saturated coverage was not reached during a continuous potential sweep when the sweep rate was relatively fast.

Weisshaar et al. reported that the coverage of dodecanethiol (C12SH) monolayers deposited electrochemically at a sweep rate of $0.1 \mathrm{~V} \mathrm{~s}^{-1}$ in $0.5 \mathrm{M} \mathrm{KOH}$ ethanol solution containing 10 $\mathrm{mM} \mathrm{C12SH}$ was typically slightly less than full coverage and that monolayers of full coverage could be formed by holding the potential at a value positive of the deposition wave for 1 min or more. ${ }^{51} \mathrm{Ma}$ and Lennox followed the potentiostatic SAM formation process by measuring the electrochemical response of the SAM modified electrode in a solution containing $\mathrm{K}_{3} \mathrm{Fe}$ $(\mathrm{CN})_{6}$ and found that the highly ordered $\mathrm{C} 12 \mathrm{SH}$ SAM was formed in $0.1 \mathrm{M} \mathrm{LiClO}_{4}$ ethanol solution containing $5 \mathrm{mM}$ $\mathrm{C} 12 \mathrm{SH}$ within 15 min. ${ }^{59}$ The present results are in good agreement with these results considering that the $\mathrm{C} 10 \mathrm{SH}$ concentrations used in the present study, which were between 


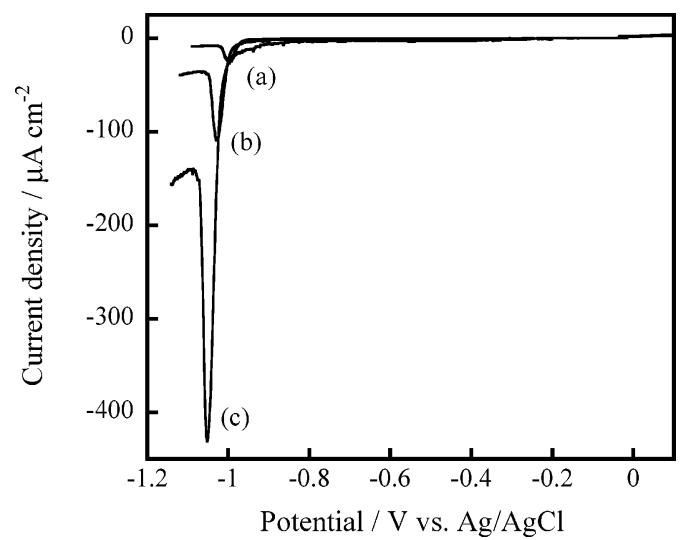

Figure 7. Linear sweep voltammograms of an $\mathrm{Au}(111)$ single crystal electrode with C10SH SAM formed anodically in $10 \mu \mathrm{M} \mathrm{C10SH}$ solution by holding the potential at $+0.1 \mathrm{~V}$ for $60 \mathrm{~min}$. Sweep rates: (a) $0.01 \mathrm{~V} \mathrm{~s}^{-1}$, (b) $0.05 \mathrm{~V} \mathrm{~s}^{-1}$, and (c) $0.2 \mathrm{~V} \mathrm{~s}^{-1}$.

$10 \mu \mathrm{M}$ and $1 \mathrm{mM}$, were much lower than the concentration of dodecanethiol they used.

The peak position shifted negatively with time, reflecting an increase in the stability of the C10SH SAM, i.e., attractive interaction among the adsorbed decanethiols. It then became constant at $-1.01 \mathrm{~V}$ in all solutions. In other words, the activity of $\mathrm{C} 10 \mathrm{~S}-\mathrm{Au}, a_{\mathrm{Cl} 10 \mathrm{~S}-\mathrm{Au}}$, decreased with time, but the final phase seemed to be the same regardless of thiol concentration. This means that the reductive peak potential is no longer given by eq 3 when a monolayer of high order is formed, and an equilibrium between the SAM and alkanethiolate ions in solution is not attained during the desorption process. It is interesting to note that the peak position continued to shift negatively even after saturated coverage had been reached. Although saturated coverage was reached within 10,6 , and 2 min in $10 \mu \mathrm{M}, 100$ $\mu \mathrm{M}$, and $1 \mathrm{mM} \mathrm{C10SH}$ solutions, respectively, the negative shift of the cathodic peak continued until 60,20 , and $10 \mathrm{~min}$ in 10 $\mu \mathrm{M}, 100 \mu \mathrm{M}$, and $1 \mathrm{mM} \mathrm{C10SH}$ solutions, respectively. This shows that the order of the SAM was still low even when full coverage had been reached and that reorganization and ordering of the SAM continued to achieve a highly ordered SAM. Similar tendencies have been seen in SAM formation without potential control in a solution containing only alkanethiol. ${ }^{10-14,21}$

Sweep Rate Dependence of Desorption Peak Potential. Figure 2 shows that the desorption potential shifted negatively as the sweep rate became faster. As already stated, the adsorbed amount is smaller when the sweep rate is faster. Thus, the results in Figure 2 are contradictory to the results in Figures 5 and 6 showing that the desorption peak shifts positively when the adsorbed amount is smaller. This suggests that the peak shift observed in Figure 2 is not controlled by the adsorbed amount but by the slow kinetics for reductive desorption. To clarify the cause of the peak shift, linear sweep voltammograms were recorded for the C10SH SAM of full coverage with higher order on a $\mathrm{Au}(111)$ single crystal electrode, which was formed in 10 $\mu \mathrm{M}$ C10SH solution by holding the potential at $+0.1 \mathrm{~V}$ for 60 min. Typical results are shown in Figure 7. The desorption peaks shifted negatively as the cathodic sweep rate was increased.

The relation between the desorption peak and the sweep rate is summarized in Figure 8. The inset of Figure 8 shows that the desorption peak potential is linearly related to the natural logarithm of the sweep rate. This dependence implies that the reductive desorption is an electrochemically irreversible process, ${ }^{34,48}$ confirming that the sweep rate-dependent peak shift shown in Figures 2 and 3 was really due to the slow kinetics of reductive desorption of the SAM.

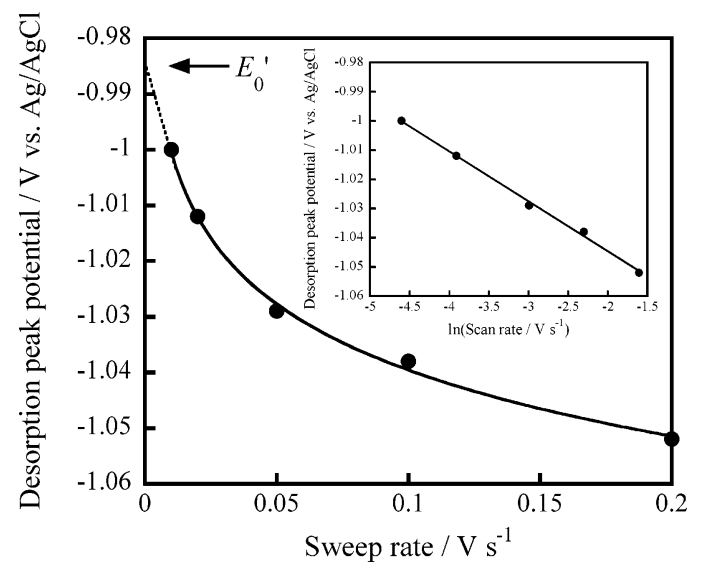

Figure 8. Sweep rate dependence of the desorption peak position of linear sweep voltammograms of a $\mathrm{Au}(111)$ single crystal electrode with C10SH SAM formed anodically in $10 \mu \mathrm{M} \mathrm{C10SH}$ solution by holding the potential at $+0.1 \mathrm{~V}$ for $60 \mathrm{~min}$. Inset: Relation between the desorption peak position and the natural logarithm of the cathodic sweep rate.

Rate Constant for the Reduction Desorption. The desorption rate constant can be estimated by ${ }^{68}$

$$
E_{\mathrm{p}}=E_{0}^{\prime}+\frac{R T}{\alpha n_{\alpha} F} \ln \left(\frac{R T}{\alpha n_{\alpha} F} \frac{k_{\mathrm{d}}^{0}}{v}\right)
$$

where $E_{\mathrm{p}}$ is the desorption peak potential, $k_{\mathrm{d}}{ }^{0}$ is the desorption rate constant at reversible potential, and $v$ is the sweep rate. Equation 5 can be rewritten as

$$
E_{\mathrm{p}}=E_{0}^{\prime}+\frac{R T}{\alpha n_{\alpha} F} \ln \left(\frac{R T}{\alpha n_{\alpha} F} k_{\mathrm{d}}^{0}\right)-\frac{R T}{\alpha n_{\alpha} F} \ln v
$$

Thus, one expects a linear relation between the logarithm of sweep rate and the desorption peak potential with a slope equal to $-R T / \alpha n_{\alpha} F$ and intercept equal to $E_{0}^{\prime}+\left(R T / \alpha n_{\alpha} F\right) \ln ((R T /$ $\left.\left.\alpha n_{\alpha} F\right) k_{\mathrm{d}}{ }^{0}\right)$. A linear relation was actually observed, as shown in the inset of Figure 8. The slope and the intercept are -0.017 and $-1.08 \mathrm{~V}$, respectively. The value of $k_{\mathrm{d}}{ }^{0}$ can be determined if $E_{0}^{\prime}$ is known. $E_{0}^{\prime}$ is estimated by extrapolating the $E_{\mathrm{p}}-$ sweep rate relation in Figure 8 to a sweep rate of 0 as 0.99 V. Since the relation is not linear, the value of $E_{0}^{\prime}$ determined by the extrapolation should contain a rather large error. A similar procedure was employed by Kakiuchi et al. ${ }^{70}$ Using these values, $k_{\mathrm{d}}{ }^{0}$ is determined to be $0.24 \mathrm{~s}^{-1}$. Vinokurov et al. determined the values of $k_{\mathrm{d}}$ at various desorption potentials for a nonanethiol SAM on a Au(111) single crystal electrode on the basis of the results of a chronoamperometric study. ${ }^{71}$ Similar measurements were carried out by Vericat et al. for a hexanethiol SAM on an evaporated gold electrode. ${ }^{49}$ Overpotential, $\left(E-E_{\mathrm{p}}\right)$, dependencies of $\log \left(k_{\mathrm{d}}\right)$, i.e., Tafel relations, are summarized in Figure 9. Extrapolations of the Tafel plots using the values obtained by Vinokurov et al. (nonanethiol) and Vericat et al. (hexanethiol) to reversible potential give $k_{\mathrm{d}}{ }^{0}$ values of 0.29 and $3.06 \mathrm{~s}^{-1}$, respectively, although the degree of accuracy of the latter is very low because only two data points are available. The $k_{d}{ }^{0}$ value of $0.24 \mathrm{~s}^{-1}$ for the electrochemically formed C10SH SAM estimated in the present study from linear sweep voltammograms with full coverage and high order is in reasonable agreement with these values obtained for a SAM prepared without potential control, indicating that the quality of an electrochemically prepared SAM is as good as that of a SAM prepared nonelectrochemically. 


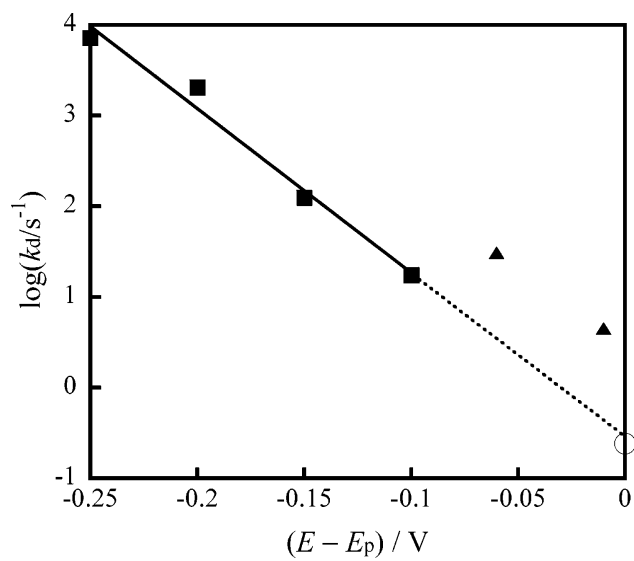

Figure 9. Desorption rate constant, $k_{\mathrm{d}}$, as a function of $\left(E-E_{\mathrm{p}}\right): \boldsymbol{\Delta}$, Vericat et al. (hexanethiol) $;{ }^{49} \mathbf{\square}$, Vinokurov et al. (nonanethiol) $;{ }^{71} \mathrm{O}$, the present work (decanethiol).

\section{Conclusions}

Electrochemical oxidative adsorption and reductive desorption of decanethiol SAMs on $\mathrm{Au}(111)$ single crystal electrodes in $0.1 \mathrm{M} \mathrm{KOH}$ ethanol solutions containing various concentrations of decanethiol were investigated. Both anodic and cathodic peaks corresponding to the oxidative adsorption and reductive desorption of the SAM, respectively, shifted negatively with an increase in the decanethiol concentration by ca. $0.057 \mathrm{~V} /$ decade at sweep rates between 0.01 and $0.2 \mathrm{~V} \mathrm{~s}^{-1}$, showing that the redox process is a one-electron process. The reductive charge increased with increase in the decanethiol concentration or decrease in the sweep rate and reached the saturated value of $103( \pm 5 \%) \mu \mathrm{C} \mathrm{cm}^{-2}$ corresponding to a SAM of full coverage with a $(\sqrt{3} \times \sqrt{ } 3) R 30^{\circ}$ structure. By holding the electrode potential at $+0.1 \mathrm{~V}$, a potential at which adsorption of decanethiol is expected, the area of the reductive desorption peak, i.e., the amount of the adsorbed decanethiol, increased and the peak position shifted negatively with increase in holding time. The times required to reach saturated coverage and a highly ordered phase became shorter with increase in the decanethiol concentration. The peak position continued to shift negatively even after saturated coverage had been reached, suggesting that the ordering of decanethiol SAMs requires a much longer time than that required for adsorption. It was also confirmed that the desorption peak shift was controlled by slow desorption kinetics rather than by the adsorbed amount of the decanethiol monolayer.

Acknowledgment. The work was partially supported by Grants-in-Aid for Scientific Research from the Ministry of Education, Culture, Sports, Science and Technology, Japan (13304047). Professor W. K. Paik and K. Shimazu are acknowledged for their useful discussions.

\section{References and Notes}

(1) Finklea, H. O. In Electroanalytical Chemistry; Bard, A. J., Rubinstein, I., Eds.; Marcel Dekker: New York, 1996; Vol. 19, p 109.

(2) Ulman, A. An Introduction To Ultrathin Organic Films: From Langmuir-Blodgett To Self-Assembly; Academic Press: San Diego, CA, 1991.

(3) Porter, M. D.; Bright, T. B.; Allara, D. L.; Chidsey, C. E. D. J. Am. Chem. Soc. 1987, 109, 3559.

(4) Laibinis, P. E.; Whitesides, G. M.; Allara, D. L.; Tao, Y.-T.; Parikh, A. N.; Nuzzo, R. G. J. Am. Chem. Soc. 1991, 113, 7152.

(5) Uosaki, K.; Kondo, T.; Zhang, X.-Q.; Yanagida, M. J. Am. Chem. Soc. 1997, 119, 8367.

(6) Bretz, R. L.; Abruña, H. D. J. Electroanal. Chem. 1996, 408, 199. 437.
(8) Bryant, M. A.; Pemberton, J. E. J. Am. Chem. Soc. 1991, 113, 8284. (9) Sato, Y.; Frey, B. L.; Corn, R. M.; Uosaki, K. Bull. Chem. Soc. Jpn. 1994, 67, 21

(10) Bensebaa, F.; Voicu, R.; Huron, L.; Ellis, T. H.; Kruus, E. Langmuir $1997,13,5335$.

(11) Shimazu, K.; Yagi, I.; Sato, Y.; Uosaki, K. Langmuir 1992, 8, 1385.

(12) Karpovich, D. S.; Blanchard, G. J. Langmuir 1994, 10, 3315.

(13) Yamada, R.; Uosaki, K. Langmuir 1997, 13, 5218.

(14) Yamada, R.; Uosaki, K. Langmuir 1998, 14, 855.

(15) Poirier, G. E. Chem. Rev. 1997, 97, 1117.

(16) Alves, C. A.; Smith, E. L.; Porter, M. D. J. Am. Chem. Soc. 1992, 114,1222

(17) Xu, S.; Cruchon-Dupeyrat, S. J. N.; Garno, J. C.; Liu, G.-Y.; Jennings, G. K.; Yong, T.-H.; Laibinis, P. E. J. Chem. Phys. 1998, 108, 5002.

(18) Camillone, N., III; Chidsey, C. D. E.; Eisenberger, P.; Fenter, P.; Li, J.; Liang, K. S.; Liu, G.-Y.; Scoles, G. J. Chem. Phys. 1993, 99, 744.

(19) Castner, D. G.; Hinds, K.; Grainger, D. W. Langmuir 1996, 12, 5083.

(20) Ishida, T.; Hara, M.; Kojima, I.; Tsuneda, S.; Nishida, N.; Sasabe, H.; Knoll, W. Langmuir 1998, 14, 2092.

(21) Dannenberger, O.; Buck, M.; Grunze, M. J. Phys. Chem. B 1999, $103,2202$.

(22) Himmelhaus, M.; Eisert, F.; Buck, M.; Grunze, M. J. Phys. Chem. B 2000, 104, 576 .

(23) Petralli-Mallow, T. P.; Briggman, K. A.; Richter, L. J.; Stephenson, J. C.; Plant, A. L. Proc. SPIE-Int. Soc. Opt. Eng. 1999, 3858, 25.

(24) Boubour, E.; Lennox, R. B. J. Phys. Chem. B 2000, 104, 9004.

(25) Protsailo, L.; Fawcett, W. R. Langmuir 2002, 18, 8933.

(26) Schönenberger, C.; Sondag-Huethorst, J. A. M.; Jorritsma, J.; Fokkink, L. G. J. Langmuir 1994, 10, 611.

(27) Sondag-Huethorst, J. A. M.; Scönenberger, C.; Fokkink, L. G. J. J. Phys. Chem. 1994, 98, 6826.

(28) Schönenberger, C.; Jorritsma, J.; Sondag-Huethorst, J. A. M.; Fokkink, L. G. J. J. Phys. Chem. 1995, 99, 3259.

(29) Yamada, R.; Sakai, H. Uosaki, K. Chem. Lett. 1999, 667.

(30) Yamada, R.; Wano, H.; Uosaki, K. Langmuir 2000, 16, 5523.

(31) Widrig, C. A.; Chung. C.; Porter, M. D. J. Electroanal. Chem. 1991 310,335 .

(32) Walczak, M. M.; Alves, C. A.; Lamp, B. D.; Porter, M. D. J. Electroanal. Chem. 1995, 396, 103.

(33) Zhong, C.-J.; Zak, J.; Porter, M. D. J. Electroanal. Chem. 1997, 421,9 .

(34) Zhong, C.-J.; Porter, M. D. J. Electroanal. Chem. 1997, 425, 147.

(35) Azehara, H.; Yoshimoto, S.; Hokari, H.; Akiba, U.; Taniguchi, I.; Fujihira, M. J. Electroanal. Chem. 1996, 473, 68.

(36) Yoshimoto, S.; Yoshida, M.; Kobayashi, S.; Nozute, S.; Miyawaki, T.; Hashimoto, Y.; Taniguchi, I. J. Electroanal. Chem. 1999, 473, 85.

(37) Oyamatsu, D.; Kuwabata, S.; Yoneyama, H. J. Electroanal. Chem. 1999, 473, 59 .

(38) Yang, D.-F.; Wilde, C. P.; Morin, M. Langmuir 1996, 12, 6570.

(39) Yang, D.-F.; Wilde, C. P.; Morin, M. Langmuir 1997, 13, 243.

(40) Calvente, J. J.; Kováčová, Z.; Sanchez, D.; Andreu, R.; Fawcett. W. R. Langmuir 1996, 12, 5696.

(41) Yang, D.-F.; Morin, M. J. Electroanal. Chem. 1998, 441, 173.

(42) Kondo, T.; Sumi, T.; Uosaki, K. J. Electroanal. Chem. 2002, $538-$ 539,59 .

(43) Yang, D.-F.; Al-Maznai, H.; Morin, M. J. Phys. Chem. B 1997, 101, 1158.

(44) Byloos, M.; Al-Maznai, H.; Morin, M. J. Phys. Chem. B 1999, 103,6554 .

(45) Schneider, T. W.; Buttry, D. A. J. Am. Chem. Soc. 1993, 115, 12391.

(46) Kawaguchi, T.; Yasuda, Y.; Shimazu, K.; Porter, M. D. Langmuir 2000, 16, 9830

(47) Hobara, D.; Miyake, K.; Imabayashi, S.; Niki, K.; Kakiuchi, T. Langmuir 1998, 14, 3590.

(48) Azzaroni, O.; Vela, M. E.; Martin, H.; Hernández-Crues, A.; Andreasen, G.; Salvarezza, R. C. Langmuir 2001, 17, 6647.

(49) Vericat, C.; Andreasen, G.; Vela, M. E.; Martin, H.; Salvarezza, R. C. J. Chem. Phys. 2001, 115, 6672.

(50) Wano, H.; Uosaki, K. Langmuir 2001, 17, 8224

(51) Weisshaar, D. E.; Lamp, B. D.; Porter, M. D. J. Am. Chem. Soc. 1992, 114,5860 .

(52) Ron, H.; Rubinstein, I. J. Am. Chem. Soc. 1998, 120, 13444.

(53) Fruböse, C.; Doblhofer, K. J. Chem. Soc. Faraday Trans. 1995, $91,1949$.

(54) Eu, S.; Paik, W. Chem. Lett. 1998, 405.

(55) Paik, W.; Eu, S.; Lee, K.; Chon, S.; Kim, M. Langmuir 2000, 16, 10198.

(56) Chon, S.; Paik, W. Phys. Chem. Chem. Phys. 2001, 3, 3405.

(57) Subramanian, R.; Lakshminarayanan, V. Electrochim. Acta 2000 45,4501 . 
(58) Qu, D.; Morin, M. J. Electroanal. Chem. 2000, 517, 45.

(59) Ma, F.; Lennox, R. B. Langmuir 2000, 16, 6188.

(60) Brett, C. M. A.; Kresak, S.; Hianik, T.; Brett, A. M. O. Electroanalysis 2003, 15, 557 .

(61) Lee, M.-T.; Hsueh, C.-C.; Freund, M. S.; Ferguson, G. S. Langmuir 2003, 19, 5246.

(62) Sumi, T.; Wano, H.; Uosaki, K. J. Electroanal. Chem. 2003, 550$551,321$.

(63) Clavilier, J.; Faure, R.; Guinet, G.; Durand, R. J. Electroanal. Chem. 1980, 107, 205

(64) Angerstein-Kozlowska, H.; Conway, B. E.; Hamelin, A.; Stoicoviciu, L. J. Electroanal. Chem. 1987, 228, 429.

(65) Hamelin, A. J. Electroanal. Chem. 1996, 407, 1.
(66) Crampton, M. R. The Chemistry of the Thiol Group: Part 1; Patai, S., Ed.; Wiley: New York, 1974.

(67) Serjeant, E. P.; Dempsey, B. Ionaization Constants of Organic Compounds in Aqueous Solutions; IUPAC Chemical Data Series No. 23; Pergamon Press: Oxford, 1983.

(68) Bard, A. J.; Faulkner, L. R. Electrochemical Methods: Fundamentals and Applications; Wiley: New York, 1980.

(69) In our previous publication, ${ }^{62}$ not total charge but Faradaic charge was plotted.

(70) Kakiuchi, T.; Usui, H.; Hobara, D.; Yamamoto, M. Langmuir 2002 18,5231 .

(71) Vinokurov, I. A.; Morin, M.; Kankare, J. J. Phys. Chem. B 2000, 104,5790 . 